\title{
Análise temporal e espacial das águas do perímetro irrigado Cotinguiba/Pindoba na região hidrográfica do baixo São Francisco Sergipano
}

\author{
Temporal and spatial analysis of the waters of the irrigated perimeter Cotinguilba/Pindoba in the \\ hydrographic region of the lower São Francisco Sergipano \\ Análisis temporal y espacial de las aguas del perímetro regado Cotinguiba/Pindoba en la región \\ hidrográfica del bajo São Francisco Sergipano
}

\author{
Amanda Oliveira Souza \\ ORCID: https://orcid.org/0000-0002-5634-8095 \\ Universidade Federal de Sergipe, Brasil \\ E-mail: amandasouza.sms@gmail.com \\ Clayton Moura de Carvalho \\ ORCID: https://orcid.org/0000-0002-4382-5382 \\ Instituto Federal de Educação, Ciência e Tecnologia Baiano, Brasil \\ E-mail: clayton.carvalho@ifbaiano.edu.br \\ Raimundo Rodrigues Gomes Filho \\ ORCID: https://orcid.org/0000-0001-5242-7581 \\ Universidade Federal de Sergipe, Brasil \\ E-mail: rrgomesfilho@hotmail.com \\ Carlos Alexandre Borges Garcia \\ ORCID: https://orcid.org/0000-0001-5260-5093 \\ Universidade Federal de Sergipe, Brasil \\ E-mail: cgarcia@ufs.br \\ Elder Sanzio Aguiar Cerqueira \\ ORCID: https://orcid.org/0000-0002-4154-4077 \\ Universidade Federal da Bahia, Brasil \\ E-mail: eldersanzio@gmail.com \\ Manoel Valnir Júnior \\ ORCID: https://orcid.org/0000-0001-7794-2184 \\ Instituto Federal de Educação, Ciência e Tecnologia do Ceará, Brasil \\ E-mail: valnir@ifce.edu.br \\ Leonaria Luna Silva de Carvalho \\ ORCID: https://orcid.org/0000-0003-4364-0537 \\ Universidade Federal do Ceará, Brasil \\ E-mail: leonarialuna@hotmail.com \\ Kleiton Rocha Saraiva \\ ORCID: https://orcid.org/0000-0003-1902-7038 \\ Instituto Federal de Educação, Ciência e Tecnologia do Piauí, Brasil \\ E-mail: kleiton.rocha@ifpi.edu.br \\ Anamália Ferreira da Silva \\ ORCID: https://orcid.org/0000-0003-0948-5684 \\ Universidade Federal de Alagoas, Brasil \\ E-mail: anamalia@outlook.com
}

\begin{abstract}
Resumo
A irrigação com um manejo inadequado pode alterar a qualidade dos recursos hídricos, diante desta informação, o objetivo desta pesquisa foi avaliar o impacto da irrigação, principalmente da rizicultura, na qualidade das águas superficiais do Perímetro de Irrigação de Cotinguiba/Pindoba, localizado na região hidrográfica do Baixo São Francisco Sergipano. Nesta pesquisa foram avaliados 22 parâmetros da qualidade da água (alcalinidade total, cálcio, cloretos, clorofila-a, coliformes termotolerantes, coliformes totais, condutividade elétrica, cor aparente, DBO, DQO, ferro dissolvido, ferro total, fósforo total, magnésio, nitrato, oxigênio dissolvido, pH, sólidos em suspensão, sólidos dissolvidos, sólidos totais, temperatura e turbidez), obtidos de dados secundários do programa de monitoramento da qualidade da água disponibilizados pela Companhia de Desenvolvimento do Vale do São Francisco e Parnaíba (CODEVASF), através dos relatórios das campanhas de monitoramento realizadas nos anos de 2006, 2013 e 2014 , e comparados com os valores estabelecidos pela resolução CONAMA 357/2005. As concentrações de fósforo total e de cor não atenderam os padrões da classe II de água doce. O valor máximo de condutividade elétrica encontrado neste estudo apresenta restrições leves a moderadas para o uso da água na irrigação. A análise da qualidade da água
\end{abstract}


permitiu evidenciar que o aporte de águas drenadas do Perímetro Cotinguiba/Pindoba contribuiu com o aumento da concentração de algumas variáveis, por isso, a importância de manter um plano de gestão ambiental para mitigar os impactos.

Palavras-chave: Qualidade da água; Poluição das águas; Recursos hídricos; Irrigação.

\begin{abstract}
Irrigation with inadequate management can alter the quality of water resources. Given this information, the objective of this research was to evaluate the impact of irrigation, especially rice growing, on the quality of surface water in the Cotinguiba/Pindoba Irrigation Perimeter, located in the region. watershed of the Lower São Francisco Sergipano. In this research, 22 water quality parameters were evaluated (total alkalinity, calcium, chlorides, chlorophyll-a, thermotolerant coliforms, total coliforms, electrical conductivity, apparent color, DBO, DQO, dissolved iron, total iron, total phosphorus, magnesium, nitrate , dissolved oxygen, $\mathrm{pH}$, suspended solids, dissolved solids, total solids, temperature and turbidity), obtained from secondary data from the water quality monitoring program provided by the São Francisco and Parnaíba Development Company (CODEVASF), through the reports of the monitoring campaigns carried out in the years 2006, 2013 and 2014, and compared with the values established by CONAMA resolution 357/2005. The concentrations of total phosphorus and color did not meet the standards of freshwater class II. The maximum value of electrical conductivity found in this study presents light to moderate restrictions for the use of water for irrigation. The analysis of water quality showed that the contribution of drained water from the Cotinguiba/Pindoba Perimeter contributed to the increase in the concentration of some variables, therefore, the importance of maintaining an environmental management plan to mitigate impacts.
\end{abstract}

Keywords: Water quality; Water pollution; Water resources; Irrigation.

\title{
Resumen
}

El riego con un manejo inadecuado puede alterar la calidad de los recursos hídricos. Ante esta información, el objetivo de esta investigación fue evaluar el impacto del riego, especialmente el cultivo de arroz, en la calidad de las aguas superficiales en el Perímetro de Riego Cotinguiba/Pindoba, ubicado en el Región Cuenca del Bajo São Francisco Sergipano. En esta investigación se evaluaron 22 parámetros de calidad del agua (alcalinidad total, calcio, cloruros, clorofila-a, coliformes termotolerantes, coliformes totales, conductividad eléctrica, color aparente, DBO, DQO, hierro disuelto, hierro total, fósforo total, magnesio, nitrato , oxígeno disuelto, $\mathrm{pH}$, sólidos en suspensión, sólidos disueltos, sólidos totales, temperatura y turbidez), obtenidos de datos secundarios del programa de monitoreo de la calidad del agua proporcionado por la Compañía de Fomento de São Francisco y Parnaíba (CODEVASF), a través de los informes de las campañas de monitoreo realizados en los años 2006, 2013 y 2014, y comparados con los valores establecidos por la resolución CONAMA 357/2005. Las concentraciones de fósforo total y color no cumplieron con los estándares de la clase II de agua dulce. El valor máximo de conductividad eléctrica encontrado en este estudio presenta restricciones de ligeras a moderadas para el uso de agua para riego. El análisis de la calidad del agua mostró que el aporte de agua drenada del Perímetro Cotinguiba / Pindoba contribuyó al incremento en la concentración de algunas variables, de ahí la importancia de mantener un plan de manejo ambiental para mitigar impactos.

Palabras clave: Calidad del agua; La contaminación del agua; Recursos hídricos; Irrigación.

\section{Introdução}

A agricultura irrigada proporciona o aumento da produção de alimentos em diferentes épocas do ano e condições climáticas em virtude da demanda mundial por água e alimento, contudo, o manejo inadequado da irrigação e drenagem são umas das principais fontes de poluição difusa dos corpos hídricos superficiais e subterrâneos (Lomba et al., 2017; Xie et al., 2018; Singh, 2019; Sales et al., 2020).

Nos últimos anos, segundo Sales et al. (2020), tem-se discutido com maior frequência a temática dos recursos hídricos em terras agrícolas, enfatizando-se as perdas em qualidade e quantidade quando adotado plantios sucessivos, ameaçando assim a sustentabilidade hídrica especialmente em regiões áridas e semiáridas.

Devido os múltiplos usos da água sem o controle ambiental correto, avaliar periodicamente parâmetros de qualidade da água torna-se fundamental como forma de controle a poluição. A única forma de se avaliar continuamente a qualidade deste bem é realizando sua análise por meio dos programas de monitoramento de qualidade da água (Maia, 2014).

A qualidade da água é, portanto, utilizada como indicador das condições do sistema aquático e para avaliar o estado de poluição, degradação ou conservação de rios, lagos, represas, estuários, águas costeiras e áreas alagadas (Vasconcelos et al., 
2009). Pode-se realizar essa avaliação utilizando-se monitoramento que é a coleta de informações regulares e a formação de um banco de dados fundamental para futuras ações referentes ao gerenciamento, uso e conservação (Villanueva et al., 2015; Carvalho et al., 2017; Carvalho et al., 2020).

Tucci (2004) discorre sobre três objetivos pelos quais se implanta uma rede de monitoramento da água: avaliar a qualidade para determinar a adequabilidade para os usos a que se destina (ex.: abastecimento público e irrigação); acompanhar a evolução da qualidade dos mananciais ao longo do tempo, como reflexo do uso e ocupação do solo e avaliação da interação do ambiente aquático com sedimentos e material biológico.

O resultado da interpretação dos dados de qualidade da água pode ser utilizado como ferramenta de gestão ambiental, no intuito de promover a conservação e preservação dos recursos hídricos. Brito et al. (2003) ratificam que a implementação de políticas de gestão e monitoramento da qualidade das águas são ações prioritárias para auxiliar na definição de medidas de prevenção e conservação dos recursos hídricos, que visem à melhoria da qualidade da água e consequentemente aumento da disponibilidade.

O Conselho Nacional de Meio Ambiente, por meio da Resolução CONAMA 357, de 17 de março de 2005, estabelece diretrizes, em território brasileiro, para classificação dos corpos d'água e para o seu enquadramento, além de outras providências. Esse instrumento jurídico fixa condições e padrões específicos, de modo a assegurar os usos preponderantes em sistemas de água doce, salobra e salina essencial à defesa de seus níveis de qualidade (Brasil, 2005).

Em diferentes países o gerenciamento integrado dos recursos hídricos, por sua relevância, desperta significativo interesse, cujo processo de gestão dos recursos hídricos engloba a capacidade de suporte do corpo hídrico, os padrões de qualidade, a emissão de poluentes, a disponibilidade tecnológica e os aspectos sociais. A comunidade científica, em todo o mundo, comumente realiza comparação entre resultados obtidos em monitoramento ambiental e os respectivos limites e enquadramentos legais associados (Cunha et al., 2013).

Diante do exposto este trabalho teve como objetivo avaliar a qualidade das águas superficiais em área de agricultura irrigada no Baixo São Francisco Sergipano, Perímetro Irrigado Cotinguiba/Pindoba, verificando o atendimento aos padrões legais da Resolução CONAMA n³57/2005.

\section{Metodologia}

\section{Caracterização da área de estudo}

A área de estudo correspondeu ao Perímetro Irrigado formado pela junção de dois povoados Cotinguiba e Pindoba, localizado entre as coordenadas geográficas UTM 24L 8868577 m e 8860105 m de latitude sul e entre UTM 24L 740720 m e $750810 \mathrm{~m}$ de longitude oeste, com altitude de aproximadamente $10 \mathrm{~m}$, Figura 1. 
Figura 1. Mapa de Localização do Perímetro Irrigado de Cotinguiba/Pindoba, Sergipe. Fonte: Dados da própria pesquisa.

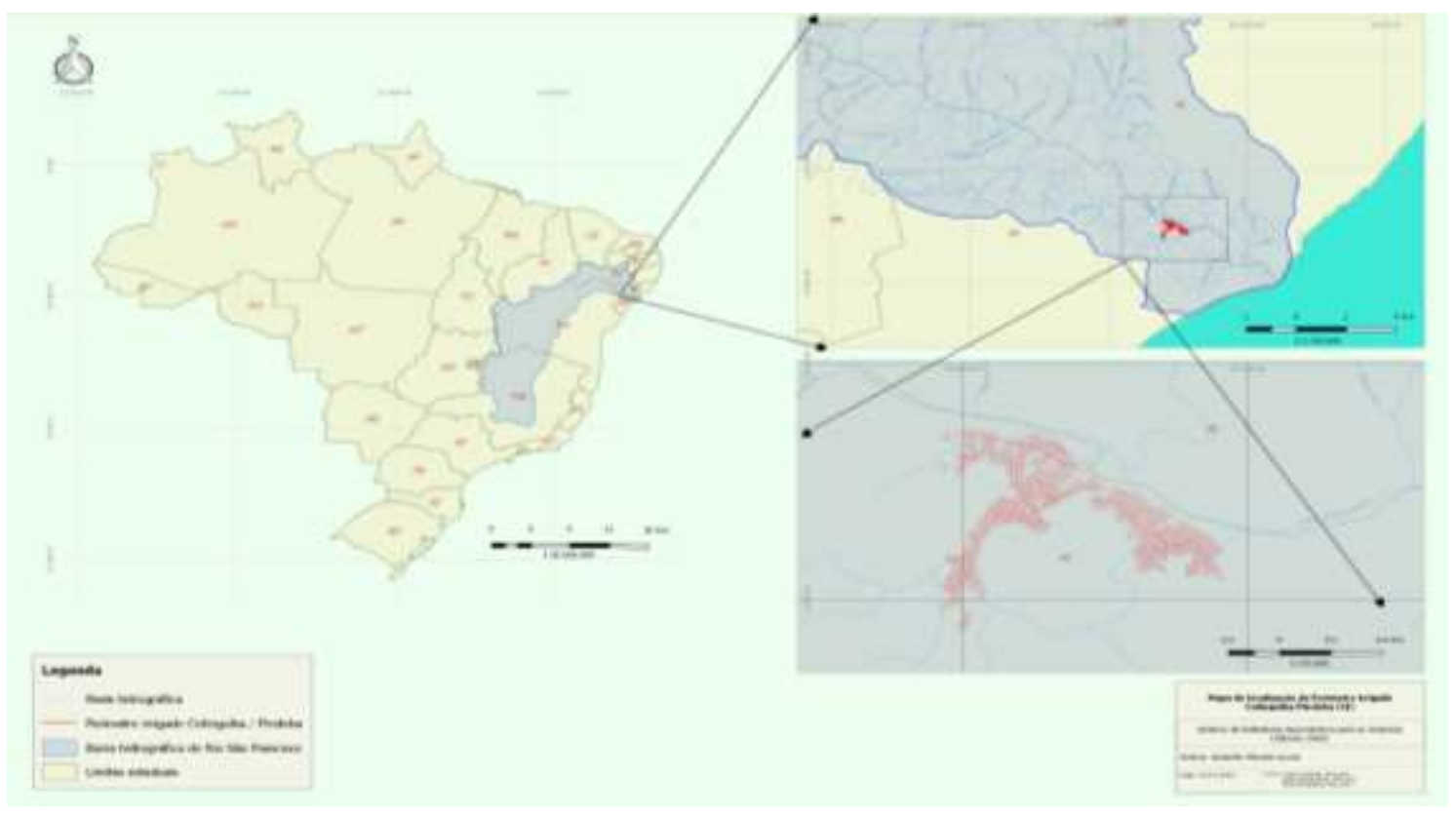

Fonte: Autores.

Conforme diretrizes do Sistema de Classificação de Uso da Terra - SCUT, a área em estudo está inserida no Território de Planejamento do Baixo São Francisco que se caracteriza pela predominância em mais de $90 \%$ de Áreas Antrópicas Agrícolas e a segunda classe mais representavia é a água. Nesta área antrópica agrícola encontram-se importantes perímetros irrigados que apresentam cultivos diversificados, tanto temporários como permanentes, em sistema de consorciação ou cultivos solteiros, além de áreas destinadas a piscicultura (IBGE, 2011).

O Perímetro Irrigado Cotinguiba/Pindoba está situado à margem direita do rio São Francisco, abrange terras dos municípios de Japoatã, Neópolis e Propriá no Estado de Sergipe. O perímetro está a 112 km da capital sergipana, Aracaju, sendo a rodovia SE-200, a principal via de acesso que se interliga a BR-101 à rodovia SE-304.

O Perímetro de Irrigação possui área total de 2.215 hectares, 474 lotes agrícolas, nos quais 85,9\% das áreas são compostas por lotes familiares, e 13,2\% por lotes empresariais (CODEVASF, 2014). As principais atividades desenvolvidas são rizicultura, policultura, carcinicultura e piscicultura. As principais culturas são: arroz, milho verde, banana e coco verde. Os métodos de irrigação implantados na área de estudo são: irrigação por aspersão convencional e inundação. Como fonte de irrigação, o rio São Francisco é o principal contribuinte. Os riachos Pilões, Nossa Senhora, Estiva e Mussuípe compõem também a hidrologia do perímetro.

O clima é do tipo semiúmido, com chuvas predominantes no outono e inverno. A precipitação média anual na área do perímetro é de $851 \mathrm{~mm}$, sendo a máxima absoluta anual de $1.074 \mathrm{~mm}$, em 1914, e a mínima de 527 mm, em 1946 (CODEVASF, 2005). As chuvas geralmente ocorrem de março a setembro, com maiores precipitações nos meses de abril a julho, sendo maio o mês mais chuvoso. O período de estiagem ocorre de outubro a fevereiro. A temperatura média anual é de $25,2^{\circ} \mathrm{C}$.

\section{Origem dos dados}

A presente pesquisa utilizou-se de dados secundários, de domínio público, do Programa de Monitoramento da Qualidade da Água disponibilizados pela Companhia de Desenvolvimento dos Vales do São Francisco e Parnaíba CODEVASF, através dos relatórios das campanhas de monitoramento realizadas nos anos de 2006 e 2014 , no Perímetro 
Irrigado de Cotinguiba/Pindoba. Os pontos de amostragem da qualidade da água do Perímetro Irrigado Cotinguiba/Pindoba podem ser observados na Figura 2.

Figura 2. Pontos de amostragem da qualidade da água do Perímetro de Irrigação Cotinguiba/Pindoba (SE). Fonte: Dados da própria pesquisa.

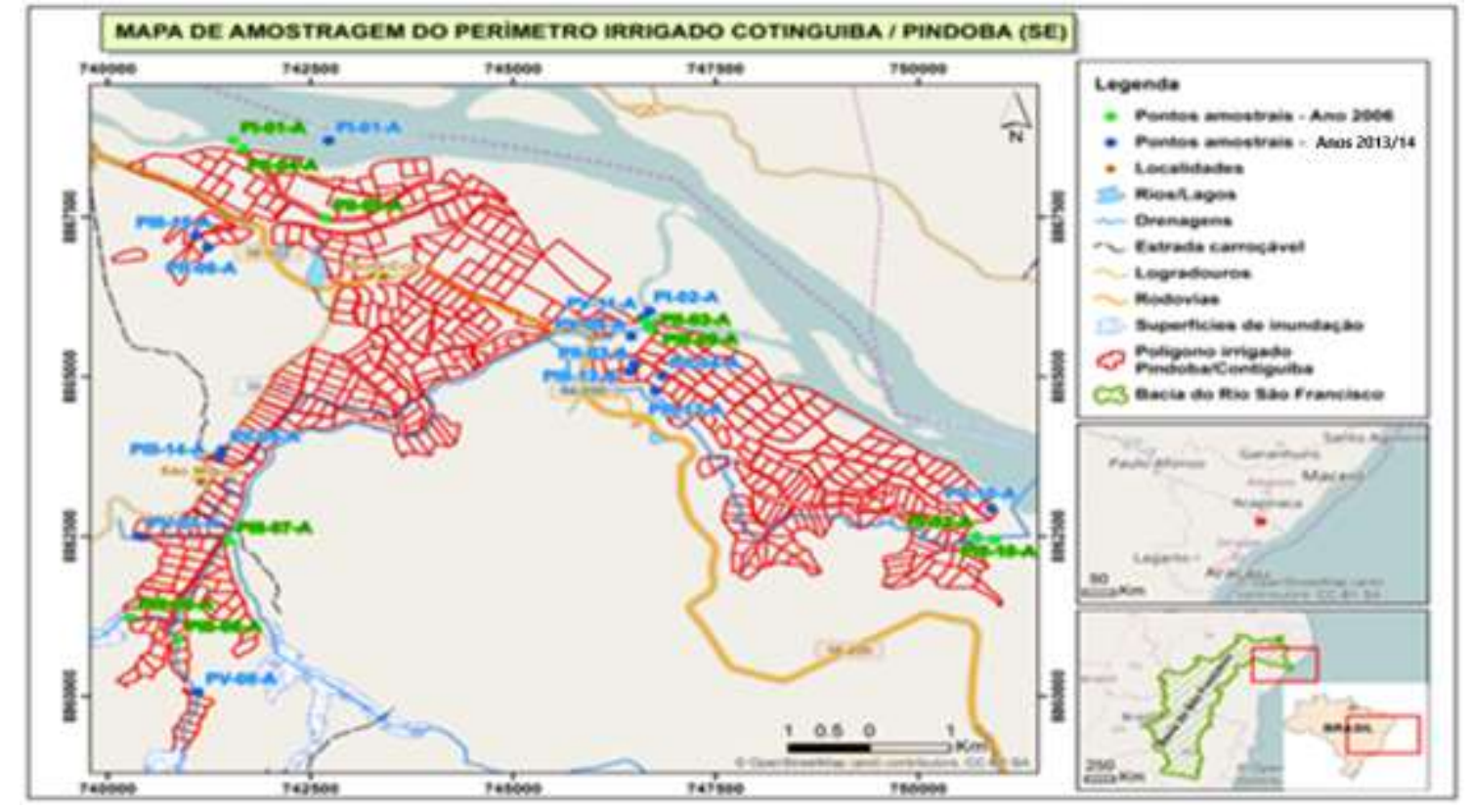

Fonte: Autores.

O Programa teve por intenção caracterizar o ambiente aquático, por meio de análises físicas, químicas e biológicas de amostras de água e sedimento, coletadas em tempo chuvoso e estiagem, entre os períodos: 30 de julho a 7 de agosto de 2013 e 4 a 10 de janeiro de 2014 (CODEVASF, 2014).

Nos anos de 2013 e 2014 foram coletadas amostras em 15 (quinze) estações amostrais distintas (Tabela 1), incluindo pontos de amostragem em drenagem de lote agrícola e de piscicultura. Nestas estações foram analisados 41 (quarenta e um) parâmetros. 
Tabela 1. Descrição das estações amostrais da rede de monitoramento da qualidade da água superficial do Perímetro Irrigado Cotinguiba/Pindoba para os anos de 2013 e 2014 Fonte: CODEVASF (2014).

\begin{tabular}{|c|c|c|c|c|c|}
\hline Ambiente & $\begin{array}{l}\text { Estação } \\
\text { amostral }\end{array}$ & Descrição & Característica principal & \multicolumn{2}{|c|}{$\begin{array}{c}\text { Coordenadas } \\
\text { Geográficas } \\
\text { 24L UTM (m) } \\
\end{array}$} \\
\hline & PI-01-A & $\begin{array}{l}\text { No leito do rio São Francisco a } \\
\text { pelo menos } 100 \text { metros a } \\
\text { montante EB } 1204\end{array}$ & $\begin{array}{l}\text { Adução de água ao } \\
\text { perímetro de irrigação }\end{array}$ & 742728 & 8868696 \\
\hline Fonte Primária I & PI-02-A & $\begin{array}{c}\text { No leito do rio São Francisco a } \\
\text { pelo menos } 100 \text { metros a } \\
\text { montante EB } 1204 \text {, zona de } \\
\text { mistura }\end{array}$ & $\begin{array}{l}\text { Adução de água ao } \\
\text { perímetro de irrigação }\end{array}$ & 746685 & 8866026 \\
\hline \multirow{4}{*}{ Multiuso II } & PII-03-A & $\begin{array}{c}\text { Na comporta de água do lote } \mathrm{n}^{\circ} \\
394\end{array}$ & $\begin{array}{c}\text { Adução de água para lote } \\
\text { piscícola }\end{array}$ & 746494 & 8865200 \\
\hline & PII-04-A & $\begin{array}{l}\text { Na comporta de água do lote } \mathrm{n}^{\circ} \\
400\end{array}$ & $\begin{array}{c}\text { Adução de água para lote } \\
\text { piscícola }\end{array}$ & 746839 & 8865008 \\
\hline & PII-05-A & $\begin{array}{l}\text { Na comporta de água do lote } \mathrm{n}^{\circ} \\
337\end{array}$ & $\begin{array}{c}\text { Adução de água para lote } \\
\text { agrícola }\end{array}$ & 741415 & 8863856 \\
\hline & PII-06-A & $\begin{array}{l}\text { Na comporta de água do lote } \mathrm{n}^{\circ} \\
495\end{array}$ & $\begin{array}{c}\text { Adução de água para lote } \\
\text { agrícola }\end{array}$ & 741233 & 8867020 \\
\hline \multirow{5}{*}{$\begin{array}{c}\text { Drenagem do } \\
\text { perímetro/coletor }\end{array}$} & PV-07-A & $\begin{array}{l}\text { Na entrada do riacho Estiva no } \\
\text { perímetro - lote } n^{\circ} 357\end{array}$ & $\begin{array}{l}\text { Drenagem de lote agrícola } \\
\text { - rizicultura }\end{array}$ & 740406 & 8862502 \\
\hline & PV-08-A & $\begin{array}{l}\text { Na entrada do riacho Pilões no } \\
\text { perímetro - lote } \text { n }^{\text {o }} 389\end{array}$ & $\begin{array}{l}\text { Drenagem de lote agrícola } \\
\text { - rizicultura }\end{array}$ & 741116 & 8860068 \\
\hline & PV-09-A & $\begin{array}{l}\text { Na entrada do riacho Mussuípe } \\
\text { no perímetro - lote } \mathrm{n}^{\circ} 237\end{array}$ & $\begin{array}{l}\text { Drenagem de lote agrícola } \\
\text { - rizicultura }\end{array}$ & 746459 & 8865626 \\
\hline & PV-10-A & $\begin{array}{l}\text { Na drenagem da EB } 1102- \\
\text { EBD } 01\end{array}$ & Drenagem do perímetro & 750903 & 8862934 \\
\hline & PV-11-A & $\begin{array}{l}\text { Na drenagem da EB } 1602- \\
\text { EBD } 02\end{array}$ & Drenagem do perímetro & 746599 & 8865926 \\
\hline \multirow{4}{*}{$\begin{array}{l}\text { Drenagem de lote } \\
\text { agrícola e ou } \\
\text { piscicultura }\end{array}$} & PIII-12-A & $\begin{array}{c}\text { Na comporta de água do lote } \mathrm{n}^{\circ} \\
394\end{array}$ & Drenagem de lote piscícola & 746438 & 8865072 \\
\hline & PIII-13-A & $\begin{array}{l}\text { Na comporta de água do lote } \mathrm{n}^{\circ} \\
400\end{array}$ & Drenagem de lote piscícola & 746755 & 8864776 \\
\hline & PIII-14-A & $\begin{array}{c}\text { Na comporta de água do lote } \mathrm{n}^{\circ} \\
337\end{array}$ & $\begin{array}{c}\text { Drenagem de lote agrícola } \\
\text { - rizicultura }\end{array}$ & 741376 & 8863740 \\
\hline & PIII-15-A & $\begin{array}{l}\text { Na comporta de água do lote } \mathrm{n}^{\circ} \\
495\end{array}$ & $\begin{array}{l}\text { Drenagem de lote agricola } \\
\text { - rizicultura }\end{array}$ & 741084 & 8867208 \\
\hline
\end{tabular}

Fonte: Autores.

No ano de 2006 foram coletadas amostras em 10 (dez) estações amostrais distintas (Tabela 2), em pontos a montante e a jusante do projeto para verificar a influência da área na qualidade das águas. Nestas estações foram analisados 30 (trinta) parâmetros. 
Tabela 2. Descrição das estações amostrais da rede de monitoramento da qualidade da água superficial do Perímetro Irrigado Cotinguiba/Pindoba para o ano de 2006. Fonte: CODEVASF (2006).

\begin{tabular}{|c|c|c|c|c|c|}
\hline Ambiente & Estação Amostral & Descrição & Característica principal & \multicolumn{2}{|c|}{$\begin{array}{l}\text { Coordenadas } \\
\text { Geográficas } \\
\text { 24L UTM (m) }\end{array}$} \\
\hline \multirow[b]{2}{*}{$\begin{array}{c}\text { Fonte } \\
\text { primária I }\end{array}$} & PI-01-A & $\begin{array}{l}\text { No leito do rio São } \\
\text { Francisco - } 100 \text { a } \\
\text { metros a montante EB } \\
1204\end{array}$ & $\begin{array}{l}\text { Adução de água ao } \\
\text { perímetro de irrigação }\end{array}$ & 741550 & 8868694 \\
\hline & PI-02-A & $\begin{array}{l}\text { No leito do rio São } \\
\text { Francisco - } 100 \text { a } \\
\text { jusante da foz do riacho } \\
\text { Mussuípe, "zona de } \\
\text { mistura". }\end{array}$ & $\begin{array}{l}\text { Águas do rio São } \\
\text { Francisco após efluência } \\
\text { das águas drenadas do } \\
\text { perímetro }\end{array}$ & 750940 & 8862442 \\
\hline \multirow{3}{*}{ Multiuso II } & PII-03-A & $\begin{array}{l}\text { No canal, após a saída } \\
\text { da EB } 0105\end{array}$ & $\begin{array}{l}\text { Águas que vão servir as } \\
\text { respectivas áreas irrigadas }\end{array}$ & 746628 & 8865866 \\
\hline & PII-04-A & $\begin{array}{l}\text { No canal, após a saída } \\
\text { da EB } 1204\end{array}$ & $\begin{array}{c}\text { de cada estação e } \\
\text { povoados. }\end{array}$ & 741668 & 8868572 \\
\hline & PII-05-A & $\begin{array}{l}\text { Na tomada d'água do } \\
\text { lote } 090 \text {, adjacente a EB } \\
1304 .\end{array}$ & & 742688 & 8867476 \\
\hline \multirow{5}{*}{$\begin{array}{c}\text { Água de } \\
\text { drenagem III }\end{array}$} & PIII-06-A & $\begin{array}{l}\text { Na entrada do riacho } \\
\text { Estiva no perímetro }\end{array}$ & $\begin{array}{c}\text { Águas dos riachos no } \\
\text { perímetro }\end{array}$ & 740281 & 8861234 \\
\hline & PIII-07-A & $\begin{array}{l}\text { Na entrada do riacho N. } \\
\text { Senhora no perímetro }\end{array}$ & & 741497 & 8862434 \\
\hline & PIII-08-A & $\begin{array}{l}\text { Na entrada do riacho } \\
\text { Pilões no perímetro }\end{array}$ & & 740876 & 8860888 \\
\hline & PIII-09-A & $\begin{array}{l}\text { Na foz do riacho Pilões, } \\
\text { próximo a EB } 0105\end{array}$ & $\begin{array}{l}\text { Águas drenadas do } \\
\text { perímetro }\end{array}$ & 746704 & 8865742 \\
\hline & PIII-10-A & $\begin{array}{l}\text { Na foz do riacho } \\
\text { Mussuípe no rio São } \\
\text { Francisco }\end{array}$ & & 750710 & 8862507 \\
\hline
\end{tabular}

Fonte: Autores.

\section{Avaliação preliminar dos dados de entrada}

A avaliação preliminar consistiu na organização e sistematização do banco de dados, para possibilitar os usos nas análises estatísticas e índices de avaliação da qualidade da água. Os dados secundários foram organizados em planilhas Excel, para cada Estação Amostral, considerando o ano de implementação da estação de monitoramento. O detalhamento de todas as etapas metodológicas utilizadas nesta pesquisa podem ser observadas no fluxograma da Figura 3. 
Figura 3. Fluxograma da metodologia de análises estatísticas e índices de qualidade utilizadas neste estudo. Fonte: Dados da própria pesquisa.

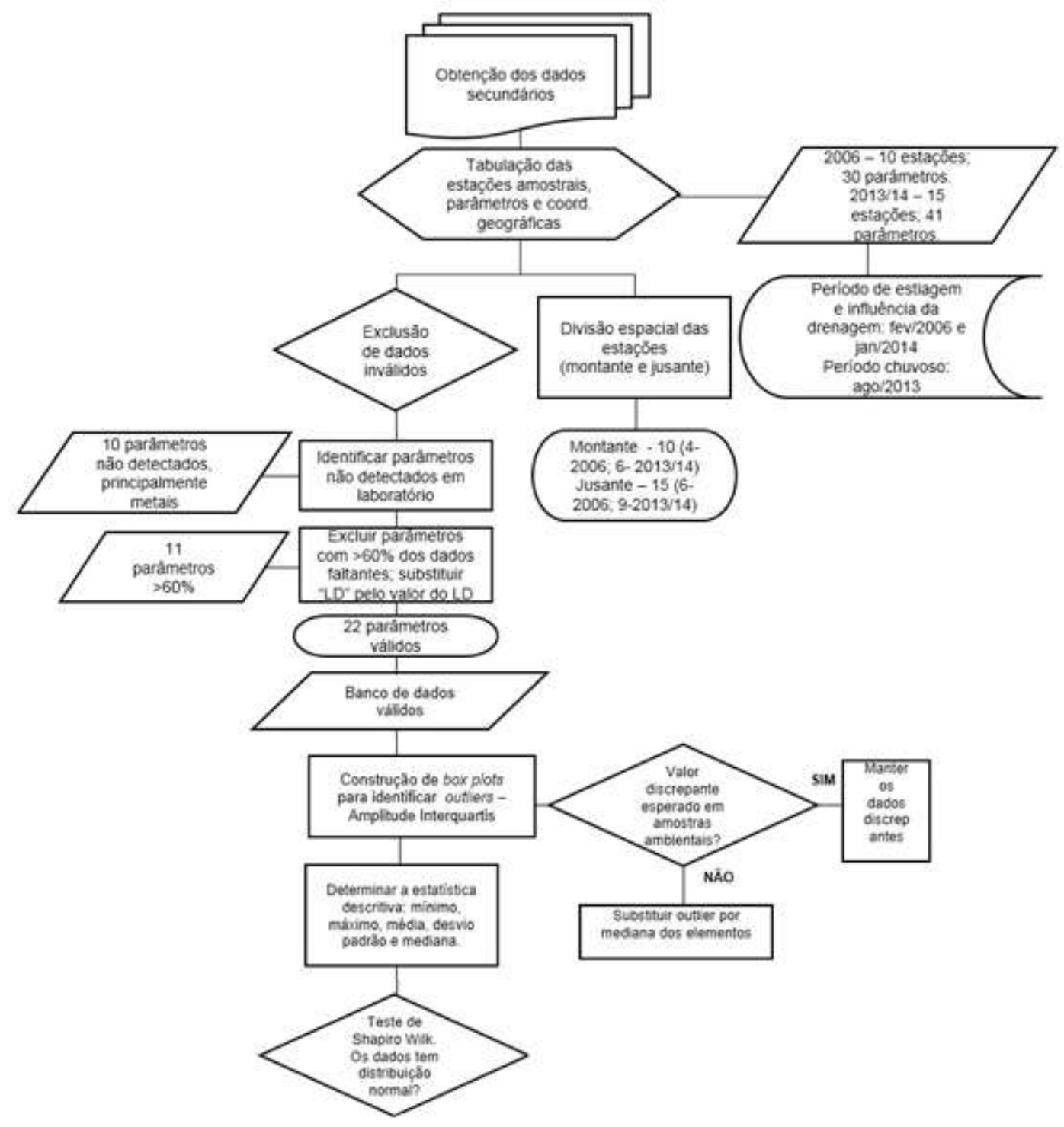

Fonte: Autores.

Neste estudo foram discutidos vinte e dois parâmetros: físicos, químicos e biológicos. Os dados de qualidade da água podem ser influenciados por: presença de outliers, de ciclos (sazonal, mensal, diário), valores faltantes, dados censurados e correlação serial (Trindade et al., 2017).

Os parâmetros analisados em cada estação de amostragem variaram de acordo com a localização da estação, com o objetivo do monitoramento e com a época do ano, ou seja, não foram avaliados todos os parâmetros em todas as estações, com isso, nem todos os parâmetros tiveram dados significativos para avaliações estatísticas, para isso foi feita uma análise de dados faltantes.

Considerando as diferentes precipitações nos meses de amostragem, este estudo abordou uma discussão de influência da sazonalidade, considerando um período de estiagem, com menor índice pluviométrico, fev/2006 e jan/2014 e um período chuvoso, ago/2013.

Brito et al. (2016) citaram que na região do Perímetro Irrigado do Betume, também localizado no Baixo São Francisco Sergipano há, nos meses de dezembro e janeiro, drenagem dos lotes de plantio, para colheita. As águas drenadas são 
direcionadas aos corpos hídricos sem nenhum tipo de tratamento. A mesma periodicidade de drenagem acontece na região em estudo (CODEVASF, 2006).

Para análise espacial da influência do perímetro de irrigação na qualidade das águas da região em estudo, as estações de monitoramento foram divididas pela sua localização, buscando dividir aquelas que não sofrem a interferência do perímetro de irrigação, a montante, chamadas também de estações de entrada e as estações de saída que estão a jusante do perímetro e que possuem como característica básica a proximidade a zonas de drenagem dos lotes de produção de arroz e pescados.

Para os 41 parâmetros analisados pela CODEVASF foram avaliados através dos critérios a seguir, para definir se seriam excluídos das análises estatísticas: elementos não detectados em análise laboratorial; percentual de dados faltantes e percentual de variância dos dados brutos em relação ao limite de detecção (LD).

Em 2006 foram obtidas 181 observações e em 2013 e 2014 foram 441 e 480 observações, respectivamente, porém alguns parâmetros, principalmente os metais, não foram detectados em análise laboratorial: Amônia (mg $\mathrm{L}^{-1}$ ); Arsênio total $\left(\mathrm{mg} \mathrm{L}^{-1}\right)$; Boro (mg L $\left.{ }^{-1}\right)$; Carbonato (Dureza) (mg L $\left.{ }^{-1}\right)$; Mercúrio (mg L $\left.{ }^{-1}\right)$; Nitrogênio amoniacal (mg L $\left.{ }^{-1}\right)$; Nitrogênio Orgânico (mg L-1); Óleos e graxas $\left(\mathrm{mg} \mathrm{L}^{-1}\right)$; Organoclorado $\left(\mathrm{mg} \mathrm{L}^{-1}\right)$; Chumbo $\left(\mathrm{mgL}^{-1}\right)$.

Os dados cujos valores tiveram 90\% de variância, inferiores ao Limite de Detecção (LD) do método analítico utilizado no laboratório, foram excluídos, considerando todas as coletas de 2006 e 2014. Para os casos em que a variância foi $<90 \%$ a referência “<LD”, que constava nos laudos de análise (CODEVASF, 2006; CODEVASF, 2014), foi substituída pelo próprio LD, haja vista que a presença destes compostos na natureza é importante para auxiliar na avaliação da degradação das águas, neste caso, esse cenário adotado é o pior possível.

Os dados faltantes foram considerados quando o parâmetro não foi avaliado em mais de $60 \%$ nas diversas estações de amostragem. Sendo assim, apenas aqueles com, no mínimo $40 \%$ dos dados válidos foram mantidos, isto para que não ocorressem falhas nas avaliações de sazonalidade e espacialidade, conforme Tabela 3.

Tabela 3. Percentual de dados faltantes para as variáveis de qualidade da água monitoradas de 2006 e $2013 / 2014$.

\begin{tabular}{lc|lc}
\hline \multicolumn{1}{c|}{ Parâmetro } & \% dados faltantes & \multicolumn{1}{c}{ Parâmetro } & \% dados faltantes \\
\hline Alcalinidade de bicarbonatos & 63,41 & Nitrato & 24,32 \\
Alcalinidade total & 17,07 & Nitrito & 63,41 \\
Cálcio & 56,10 & Organofosforado & 63,41 \\
Carbono orgânico total & 63,41 & Oxigênio dissolvido & 31,71 \\
Cloretos & 56,10 & pH & 0,00 \\
Clorofila-a & 26,83 & Potássio & 63,41 \\
Coliformes termotolerantes & 43,90 & Sódio Total & 63,41 \\
Coliformes totais & 39,02 & Sólidos dissolvidos & 0,00 \\
Condutividade elétrica & 24,39 & Sólidos suspensos & 24,39 \\
Cor aparente & 24,39 & Sólidos totais & 19,51 \\
DBO & 0,00 & Temperatura & 0,00 \\
DQO & 43,90 & Turbidez & 0,00 \\
Ferro dissolvido & 56,10 & Amônia & 90,24 \\
Ferro total & 24,39 & Carbonato Dureza & 92,68 \\
Fosforo total & 24,39 & Nitrogênio Orgânico & 75,61 \\
Fosforo dissolvido & Sódio & 92,68 \\
Magnésio & 50,49 & & \\
\hline
\end{tabular}

Fonte: Autores.

Dos 33 parâmetros que foram avaliados e tiveram valores acima do limite de detecção do método (LD), 11 apresentaram mais de $60 \%$ dos dados faltantes, neste caso foram excluídos. Logo, 22 parâmetros foram avaliados nesta pesquisa, são eles: alcalinidade total; cálcio; cloretos; clorofila-a; coliformes termotolerantes; coliformes totais; condutividade 
elétrica; cor; DBO; DQO; ferro dissolvido; ferro total; fósforo total; magnésio; nitrato; oxigênio dissolvido; pH; sólidos em suspensão; sólidos dissolvidos; sólidos totais; temperatura e turbidez.

Após a definição de dados válidos, as próximas análises foram determinação da estatística descritiva e identificação de outlier. Os valores médios de cada variável foram comparados com os padrões de qualidade estabelecidos na Resolução CONAMA nº 357 (Brasil, 2005) para os corpos hídricos de água doce.

\section{Verificação da presença de outliers pelo gráfico Boxplot}

As análises estatísticas e índices de qualidade da água foram precedidas da verificação de dados discrepantes, outliers. Utilizou-se a verificação da presença de outliers pelo gráfico Boxplot. Lisboa et al. (2016), ao avaliarem parâmetros hidrogeológicos, utilizaram essa verificação e excluíram outliers para não interferir nos testes estatísticos.

O boxplot representa graficamente o método exploratório da Amplitude Interquartis (AIQ), que é utilizado para identificação de outliers, dada pela diferença entre Q3 e Q1, respectivamente, o primeiro e o terceiro quartis, logo foram considerados discrepantes, para este estudo, os valores maiores do que Q3+1,5*(Q3-Q1) ou menores do que Q1 - 1, $5 *$ (Q3 - Q1) (Naghettini \& Pinto, 2007).

Ainda segundo esses autores, o gráfico boxplot apresenta as frequências acumuladas e permite a identificação imediata da mediana Q2, qual seja do valor correspondente à frequência de não superação de 0,5 , assim como do primeiro quartil Q1 e do terceiro quartil Q3, que correspondem respectivamente às frequências de 0,25 e 0,75.

\section{Resultados e Discussão}

\section{Estatística descritiva}

A primeira análise estatística foi o cálculo de média, desvio padrão, percentis $(10,25,50,75$ e 90) e percentual de outliers. O critério para decidir se uma observação é discrepante pode variar. Cada parâmetro foi avaliado individualmente para identificar valores discrepantes, utilizou-se o boxplot para auxílio, conforme Figura 4. Nem todos os casos de inconsistência foram excluídos dos bancos de dados, já que podem ocorrer naturalmente em dados ambientais segundo Sabino et al. (2014).

Figura 4. Boxplots dos parâmetros de qualidade avaliados.

A

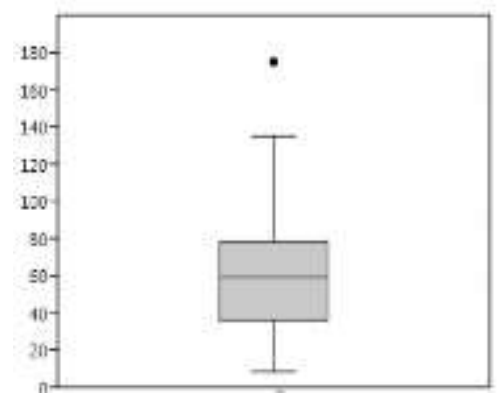

D

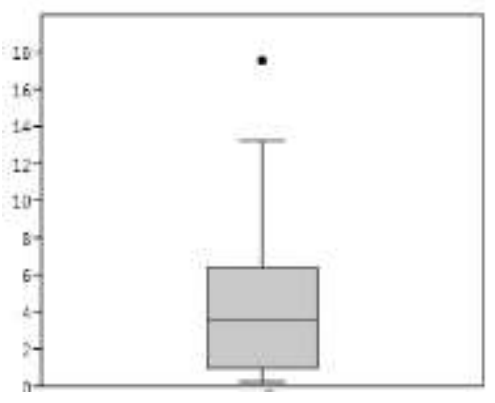

B

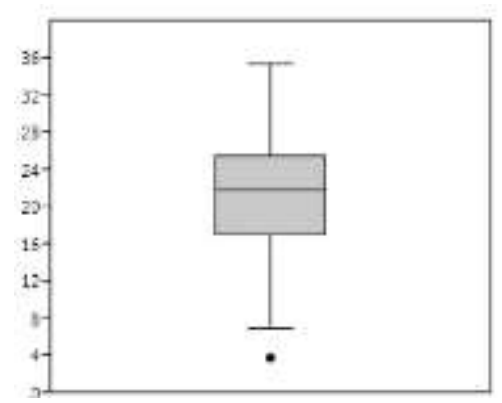

E

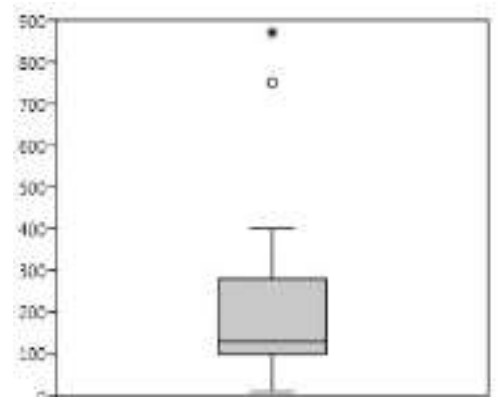

C

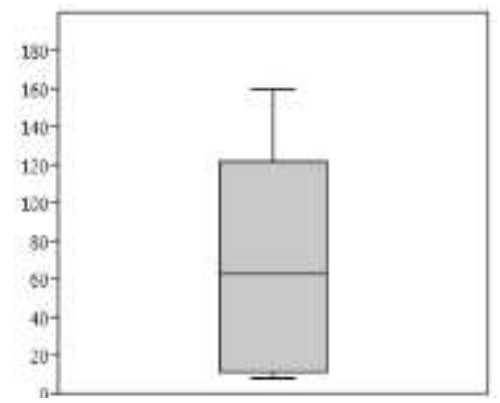

F

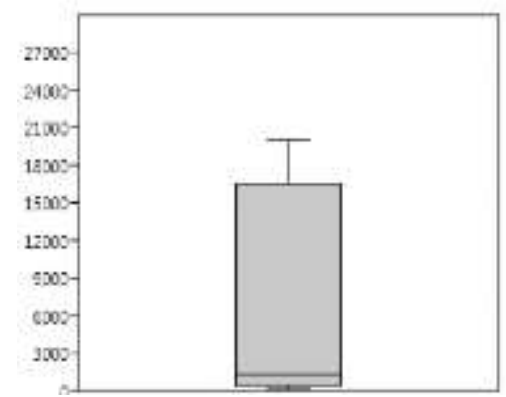


Research, Society and Development, v. 10, n. 2, e39210212403, 2021

(CC BY 4.0) | ISSN 2525-3409 | DOI: http://dx.doi.org/10.33448/rsd-v10i2.12403

G

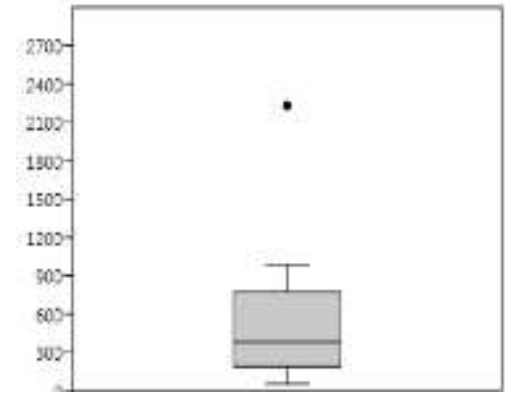

$\mathbf{J}$

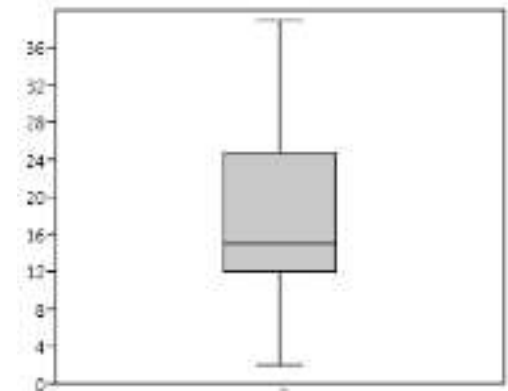

M

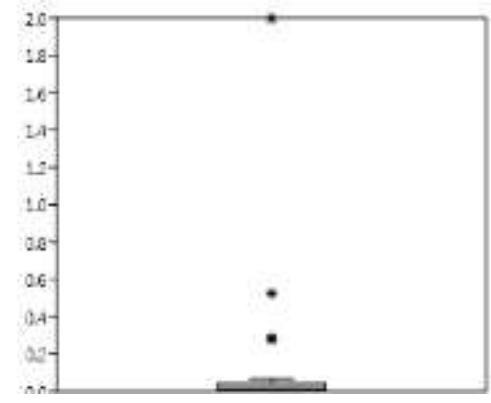

$\mathbf{P}$

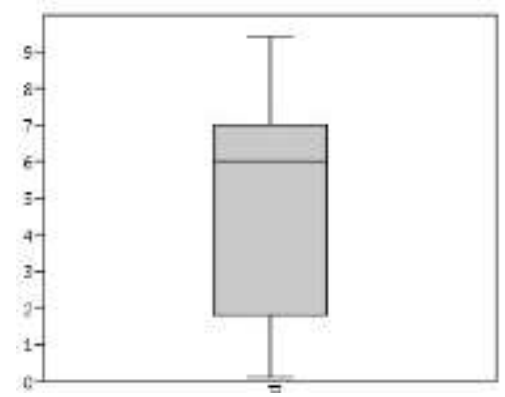

$\mathbf{S}$

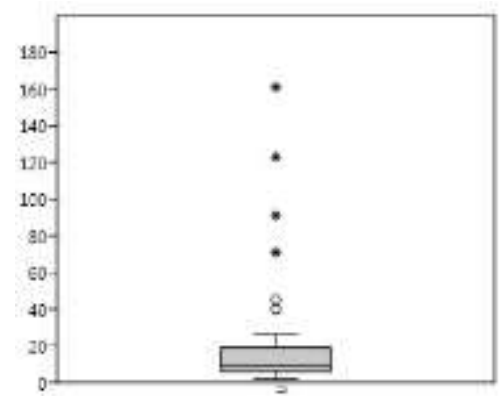

H

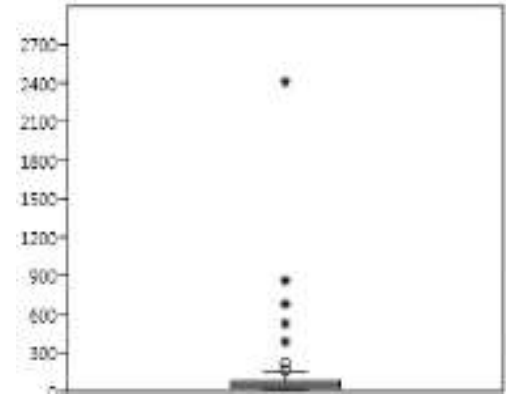

$\mathbf{K}$

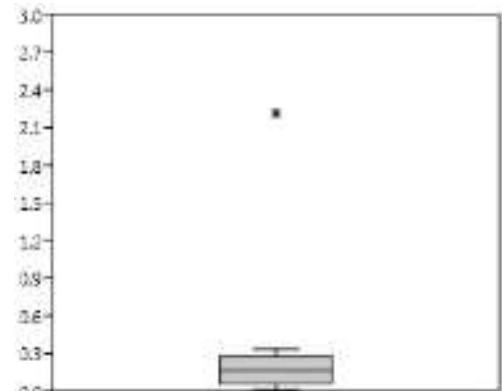

$\mathbf{N}$

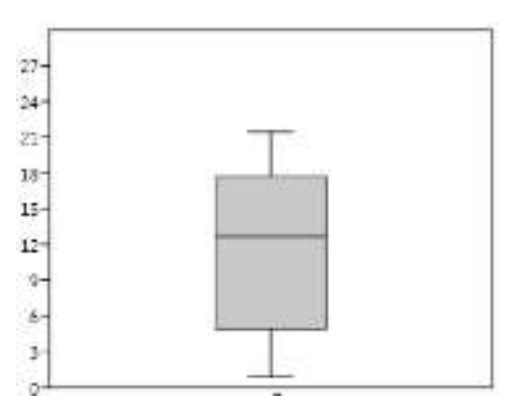

Q

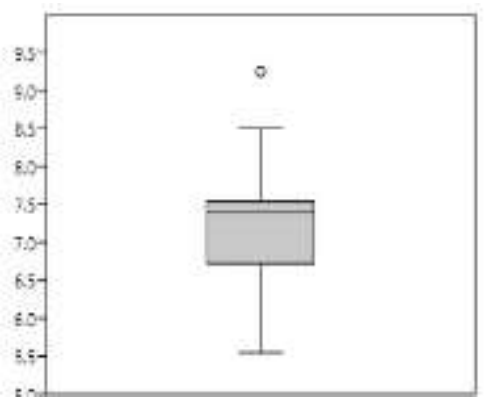

T

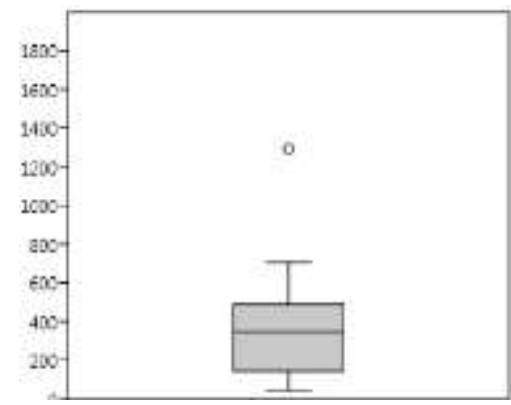

I

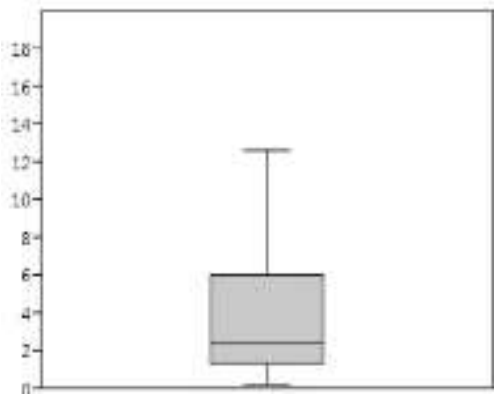

L

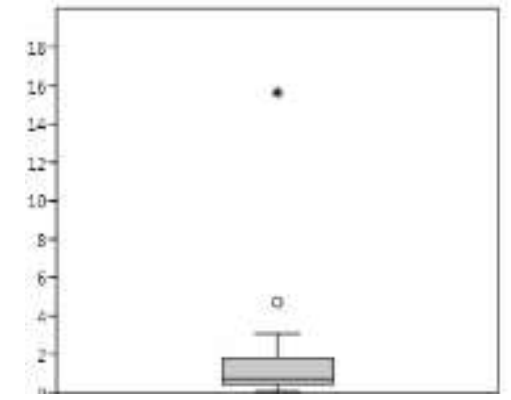

O

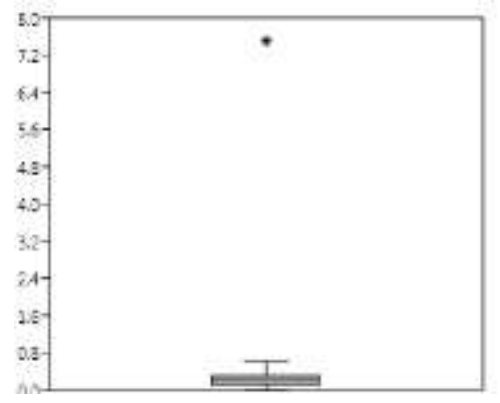

R

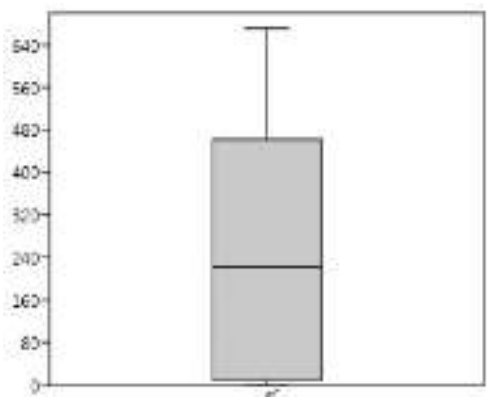

U

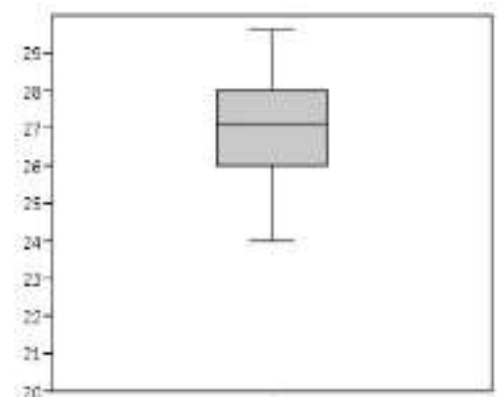




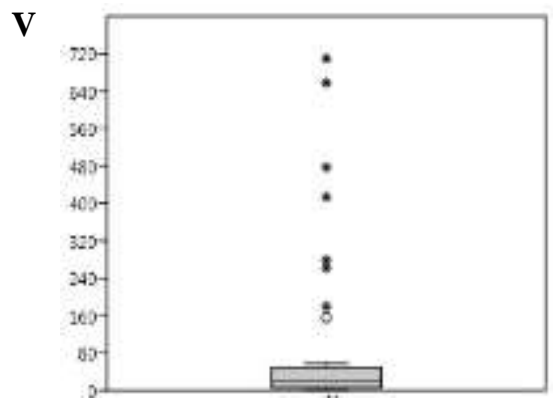

A - Alcalinidade total $\left(\mathrm{mg} \mathrm{L}^{-1}\right) ; \mathbf{B}$ - Cálcio $\left(\mathrm{mg} \mathrm{L}^{-1}\right) ; \mathbf{C}$ - Cloretos $\left(\mathrm{mg} \mathrm{L}^{-1}\right)$;

D - Clorofila-a (ug L $\left.{ }^{-1}\right) ; \mathbf{E}$ - Coliformes fecais (termotolerantes) (UFC);

F - Coliformes totais (UFC); $\mathbf{G}$ - Condutividade elétrica $\left(\mu \mathrm{S} \mathrm{cm}^{-1}\right)$;

$\mathbf{H}$ - Cor aparente (UC); I - DBO $\left(\mathrm{mg} \mathrm{L}^{-1}\right) ; \mathbf{J}$ - DQO $\left(\mathrm{mg} \mathrm{L}^{-1}\right)$;

$\mathbf{K}$ - Ferro dissolvido $\left(\mathrm{mg} \mathrm{L}^{-1}\right) ; \mathbf{L}$ - Ferro total $\left(\mathrm{mg} \mathrm{L}^{-1}\right)$;

$\mathbf{M}$ - Fósforo total $\left(\mathrm{mg} \mathrm{L}^{-1}\right) ; \mathbf{N}$ - Magnésio $\left(\mathrm{mg} \mathrm{L}^{-1}\right) ; \mathbf{O}$ - Nitrato $\left(\mathrm{mg} \mathrm{L}^{-1}\right)$;

$\mathbf{P}$ - Oxigênio dissolvido $\left(\mathrm{mg} \mathrm{L}^{-1}\right) ; \mathbf{Q}$ - $\mathrm{pH} ; \mathbf{R}$ - sólidos dissolvidos;

$\mathbf{S}$ - Sólidos suspensos $\left(\mathrm{mg} \mathrm{L}^{-1}\right)$; $\mathbf{T}$ - Sólidos totais $\left(\mathrm{mg} \mathrm{L}^{-1}\right)$;

$\mathbf{U}$ - Temperatura da amostra $\left({ }^{\circ} \mathrm{C}\right) ; \mathbf{V}$ - Turbidez (NUT).

Fonte: Dados da própria pesquisa.

Através das análises da Figura 4, verificou-se que alguns parâmetros tiveram amostras que desviaram significativamente dos outros elementos da amostra. Na maioria desses casos registrados, os valores discrepantes foram substituídos pelo valor mediano do parâmetro durante o período de monitoramento.

Dos 22 parâmetros analisados, 14 apresentaram percentual de valores discrepantes, Tabela 4, foram eles: Alcalinidade total $\left(\mathrm{mg} \mathrm{L}^{-1}\right)$; Cálcio $\left(\mathrm{mg} \mathrm{L}^{-1}\right)$; Clorofila a $\left(\mathrm{ug} \mathrm{L}^{-1}\right)$; Coliformes fecais (termotolerantes) (UFC); Condutividade elétrica $\left(\mu \mathrm{S} \mathrm{cm}^{-1}\right)$; Cor aparente $(\mathrm{UC})$; Ferro total $\left(\mathrm{mg} \mathrm{L}^{-1}\right)$; Ferro dissolvido $\left(\mathrm{mg} \mathrm{L}^{-1}\right)$; Fosforo total $\left(\mathrm{mg} \mathrm{L}^{-1}\right)$; Nitrato $\left(\mathrm{mg} \mathrm{L}^{-1}\right)$; pH; Sólidos suspensos (mg L $\left.{ }^{-1}\right)$; Sólidos totais $\left(\mathrm{mg} \mathrm{L}^{-1}\right)$; Turbidez (NUT).

Tabela 4. Descrição dos parâmetros e \% outlier identificado através do método de amplitude interquartil. Fonte: Dados da própria pesquisa.

\begin{tabular}{|c|c|c|c|}
\hline Parâmetro & $\%$ outlier & Parâmetro & $\%$ outlier \\
\hline Alcalinidade total & 3 & Ferro total & 6 \\
\hline Cálcio & 6 & Fósforo total & 10 \\
\hline Cloretos & 0 & Magnésio & 0 \\
\hline Clorofila a & 3 & Nitrato & 7 \\
\hline Coliformes termotolerantes & 9 & Oxigênio dissolvido & 0 \\
\hline Coliformes totais & 0 & $\mathrm{pH}$ & 2 \\
\hline Condutividade elétrica & 3 & Sólidos dissolvidos & 0 \\
\hline Cor aparente & 23 & Sólidos suspensos & 19 \\
\hline $\mathrm{DBO}$ & 0 & Sólidos totais & 3 \\
\hline DQO & 0 & Temperatura & 0 \\
\hline Ferro dissolvido & 6 & Turbidez & 20 \\
\hline
\end{tabular}

Fonte: Autores.

As variáveis turbidez, sólidos suspensos, e coliformes termotolerantes, apesar de apresentarem valores discrepantes, foram mantidas. No caso do fósforo total apenas um outlier foi substituído pela mediana, o restante era esperado em amostras ambientais. Os demais foram substituídos pela mediana: Alcalinidade total ( $\left.\mathrm{mg} \mathrm{L}^{-1}\right)$; Cálcio ( $\left.\mathrm{mg} \mathrm{L}^{-1}\right)$; $\mathrm{Clorofila} \mathrm{a} \mathrm{(ug} \mathrm{L}^{-1}$ );

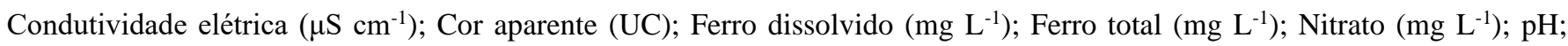
Potássio $\left(\mathrm{mg} \mathrm{L}^{-1}\right)$ e Sólidos totais $\left(\mathrm{mg} \mathrm{L}^{-1}\right)$.

Após definição dos dados válidos, calcularam-se os dados de estatística descritiva, Tabela 5. Para cada variável foi avaliado, ainda, se os dados seguiam ou não a distribuição normal. O teste de Normalidade Shapiro-Wilk, ao nível de significância de 5\%, foi utilizado usando o Past 3.07, para verificar o comportamento simétrico ou assimétrico dos dados, dados apresentados na Tabela 6. 
Tabela 5 - Estatística descritiva do banco de dados válidos. Fonte: Dados da própria pesquisa.

\begin{tabular}{|c|c|c|c|c|c|c|c|c|c|c|c|}
\hline Parâmetro & Alc $\mathbf{T}$ & Ca & $\mathrm{Cl}^{-}$ & Cl-a & $\begin{array}{l}\text { CLF } \\
\text { Term. }\end{array}$ & $\begin{array}{l}\text { CLF } \\
\text { Total }\end{array}$ & CE & Cor & DBO & DQO & Fe dis. \\
\hline Unidade & mg.L - $^{-1}$ & mg... $\mathrm{L}^{-1}$ & mg.L. ${ }^{-1}$ & mg... $\mathrm{L}^{-1}$ & UFC & UFC & $\mu \mathrm{S} . \mathrm{cm}^{-1}$ & $\mathrm{UC}$ & mg.L. ${ }^{-1}$ & $\mathrm{mg} . \mathrm{L}^{-1}$ & mg. $\mathrm{L}^{-1}$ \\
\hline Mínimo & 8,4 & 6,9 & 8,1 & 0,2 & 10 & 130 & 55 & 11 & 0,2 & 2,0 & 0 \\
\hline Máximo & 135,0 & 35,3 & 159,7 & 13,2 & 870 & 20000 & 989 & 2408 & 12,6 & 38,9 & 2,2 \\
\hline Média & 54,6 & 21,8 & 69 & 4,0 & 198,5 & 6829 & 444,3 & 173,3 & 3,4 & 17,1 & 0,3 \\
\hline $\begin{array}{l}\text { Desvio } \\
\text { padrão }\end{array}$ & 5,1 & 1,9 & 13,5 & 0,7 & 45,5 & 1689,2 & 48,1 & 65,9 & 0,4 & 2,1 & 0,1 \\
\hline Mediana & 55,9 & 21,7 & 62,6 & 2,7 & 130,0 & 1300,0 & 382,0 & 50 & 2,4 & 15,0 & 0,1 \\
\hline Percentil 25 & 34,0 & 17,4 & 11,1 & 1,0 & 100,0 & 418,0 & 188,4 & 26 & 1,3 & 12,0 & 0,1 \\
\hline $\begin{array}{c}\text { Percentil } 75 \\
\text { Média }\end{array}$ & 75,8 & 25,7 & 122,1 & 6,3 & 280,0 & 16520 & 729,0 & 78 & 5,6 & 24,7 & 0,3 \\
\hline geométrica & 45,1 & 20,1 & 40,8 & 2,3 & 118,3 & 2026,5 & 321,1 & 62,3 & 2,5 & 13,9 & 0,1 \\
\hline Parâmetro & Fe total & $\mathbf{P}_{\text {Total }}$ & Mg & $\mathrm{NO}_{3}{ }^{-1}$ & OD & pH & S. Diss & S. Susp & S. Total & $\mathbf{T}$ & Turb \\
\hline Unidade & mg.L.' & mg.L ${ }^{-1}$ & mg.L ${ }^{-1}$ & mg.L.' & mg.L.$^{-1}$ & - & mg.L. ${ }^{-1}$ & mg.L.' & mg.L ${ }^{-1}$ & ${ }^{\circ} \mathbf{C}$ & NUT \\
\hline Mínimo & 0,1 & 0,0 & 0,9 & 0,0 & 0,1 & 5,6 & 1,0 & 2,0 & 44,0 & 24,0 & 0,8 \\
\hline Máximo & 4,7 & 2,0 & 21,5 & 0,6 & 9,4 & 8,5 & 671 & 161 & 706 & 29,6 & 710 \\
\hline Média & 1,1 & 0,1 & 11,4 & 0,2 & 4,8 & 7,2 & 244,8 & 24,4 & 333,8 & 27,0 & 90,9 \\
\hline $\begin{array}{l}\text { Desvio } \\
\text { padrão }\end{array}$ & 0,2 & 0,1 & 1,6 & 0,0 & 0,5 & 0,1 & 33,5 & 6,7 & 34,6 & 0,2 & 27,3 \\
\hline Mediana & 0,7 & 0,0 & 12,7 & 0,2 & 6,0 & 7,4 & 222 & 9,0 & 347 & 27,1 & 19,5 \\
\hline Percentil 25 & 0,4 & 0,0 & 6,2 & 0,1 & 1,8 & 6,8 & 24,4 & 6,0 & 145,5 & 26,0 & 6,6 \\
\hline $\begin{array}{c}\text { Percentil } 75 \\
\text { Média }\end{array}$ & 1,7 & 0,0 & 17,2 & 0,3 & 7,0 & 7,5 & 438,5 & 19,0 & 478,0 & 27,9 & 46,7 \\
\hline geométrica & 0,7 & 0,0 & 8,4 & 0,1 & 3,0 & 7,1 & 75,5 & 12,0 & 260,5 & 26,9 & 21,2 \\
\hline
\end{tabular}

Fonte: Autores.

Tabela 6 - Teste de normalidade de Shapiro-Wilk, p (normal). Fonte: Dados da própria pesquisa

\begin{tabular}{lc|lc}
\hline \multicolumn{1}{c|}{ Parâmetro } & Teste & \multicolumn{1}{c}{ Parâmetro } & Teste \\
\hline Alcalinidade total & $0,2621^{*}$ & Ferro total & 0,0002 \\
Cálcio & $0,6109^{*}$ & Fosforo total & 0,000000379 \\
Cloretos & 0,0108 & Magnésio & $0,4890^{*}$ \\
Clorofila a & 0,0019 & Nitrato & 0,0022 \\
Coliformes termotolerantes & 0,0322 & Oxigênio dissolvido & 0,0044 \\
Coliformes totais & 0,00000822 & pH & 0,0372 \\
Condutividade elétrica & 0,0057 & Sólidos dissolvidos & 0,0023 \\
Cor aparente & 0,0000000189 & Sólidos suspensos & 0,0000454 \\
DBO & 0,0001 & Sólidos totais & $0,1626^{*}$ \\
DQO & $0,1375^{*}$ & Temperatura & $0,2336^{*}$ \\
Ferro dissolvido & 0,000350 & Turbidez & 0,000000631 \\
\hline
\end{tabular}

* $\mathrm{p}>0,05$, distribuição normal. Fonte: Autores.

Dos 22 parâmetros, alcalinidade total; cálcio; DQO; magnésio; sólidos totais e temperatura apresentaram distribuição normal.

Considerando os desvios padrões, coliformes totais, cor aparente, coliformes termotolerantes, condutividade elétrica, sólidos totais, sólidos dissolvidos e temperatura apresentaram maiores variações. Zucco et al. (2012), ao avaliarem qualidade das águas em uma bacia agrícola, detectaram que os parâmetros que mais variaram foram pH, turbidez e nitrogênio amoniacal.

A Resolução CONAMA 357/2005 (Brasil, 2005) não estabelece padrões relativos à condutividade elétrica de águas, porém o critério de salinidade, normalmente, é avaliado em função deste parâmetro, onde valores menores que 0,75 dS.m ${ }^{-1}$ não apresenta restrição ao uso para irrigação, valores entre 0,75 e $3 \mathrm{dS} \mathrm{m} \mathrm{m}^{-1}$ apresenta restrição ligeira a moderada e, com valores 
maiores que 3,0 dS m${ }^{-1}$ apresenta severa restrição ao uso (Ayers \& Westcot, 1994). Neste estudo a condutividade elétrica variou de 0,055 a $0,989 \mathrm{dS} \cdot \mathrm{m}^{-1}$.

Este valor máximo de condutividade elétrica apresenta restrição ligeira a moderada para o seu uso na irrigação de acordo com a classificação das águas para fins de irrigação. Tais valores elevados são esperados em ambientes poluídos por esgotos domésticos ou industriais, onde os valores podem chegar a $1 \mathrm{dS} \mathrm{m}^{-1}$, enquanto que as águas naturais apresentam teores de condutividade na faixa de 0,010 a $0,10 \mathrm{dS} \mathrm{m}^{-1}$ (Brasil, 2014).

Os níveis de sais e nutrientes são impulsionados principalmente pela quantidade e qualidade da água lixiviada de origem agrícola, e trabalhos têm indicado a correlação da drenagem agrícola no processo de degradação da qualidade, da mesma forma que pode limitar a disponibilidade de água em regiões a jusante (Van Vliet et al., 2017; Hu et al., 2019; Sales et al., 2020).

Medeiros et al. (2013) avaliaram a vulnerabilidade ambiental na qualidade das águas superficiais da Bacia do Córrego das Antas, Tupi Paulista/SP e encontraram valores elevados de condutividade elétrica, os autores atribuíram ao intemperismo químico dos arenitos rico em ferro.

Queiroz et al. (2010), ao avaliarem qualidade das águas de uma bacia com predominância de uso do solo da agricultura, detectaram valores baixos de condutividade elétrica, entre 12 e $19 \mu \mathrm{s} \mathrm{cm}^{-1}$, apesar de atribuírem variações de condutividade elétrica na água à entrada de fertilizantes e defensivos agrícolas que acabam aumentando as concentrações iônicas nos corpos d'água.

Menezes et al. (2016) sugeriram que após a passagem por lotes irrigados, a água retorna com uma qualidade deteriorada, possivelmente devido ao mau uso do solo e da água nos cultivos agrícolas.

Os níveis de clorofila-a foram todos inferiores a $30 \mathrm{ug} \mathrm{L}^{-1}$, tendo valor máximo de $11,77 \mathrm{ug} \mathrm{L}^{-1}$, no período de estiagem e 13,21 ug L L ${ }^{-1}$ no período chuvoso, o que classificaria os corpos hídricos como Classe 2 de acordo com a Resolução CONAMA 357/2005 (Brasil, 2005). A concentração máxima de fósforo total no período chuvoso foi de 0,524 mg.L e no período de estiagem foi de $0,284 \mathrm{mg} \mathrm{L}^{-1}$, logo não enquadraria o corpo hídrico em nenhuma das Classes da Resolução CONAMA 357/2005, já que os resultados não atenderam aos limites preconizados na legislação.

A referida Resolução do CONAMA define os limites máximos nas Classes 1, 2 e 3 para os parâmetros de Clorofila-a e Fósforo total, são respectivamente $10 \mu \mathrm{g} \mathrm{L}^{-1}$ e $0,1 \mathrm{mg} \mathrm{L}^{-1}, 30 \mu \mathrm{g} \mathrm{L}^{-1}$ e $0,1 \mathrm{mg} \mathrm{L}^{-1}$ e $60 \mu \mathrm{g} \mathrm{L}^{-1}$ e $0,15 \mathrm{mg} \mathrm{L}^{-1}$ (Brasil, 2005).

O cenário ideal de qualidade da água sob o aspecto legal para a área em estudo é atender os limites estabelecidos para a Classe 2, já que esta classe enquadra os parâmetros para que as águas sejam destinadas ao abastecimento para consumo humano, após tratamento convencional; à proteção das comunidades aquáticas; à recreação de contato primário; à irrigação; à aquicultura e à atividade de pesca (Brasil, 2005).

Buzelli \& Cunha-Santino (2013) realizaram diagnóstico da qualidade da água e estado trófico do reservatório de Barra Bonita, SP e classificaram a clorofila-a como uma importante variável nos ecossistemas aquáticos, sendo o principal pigmento responsável pelo processo de fotossíntese, além de ser um indicador do estado trófico dos ambientes aquáticos. O aumento das taxas de clorofila-a é proveniente do despejo de esgoto doméstico não tratado ou de intensas atividades agrícolas que ocupam a maior parte dentre os usos do solo da região.

Oliveira (2002) detectou em seu estudo que a clorofila-a correlaciona-se negativamente com os sólidos totais dissolvidos, quanto maior a concentração de sedimento, menor é a colonização das algas, pois indica a biomassa de algas presente no corpo hídrico, consequentemente a concentração de nutrientes na água.

Em bacias hidrográficas que possuem uso para fins de agricultura irrigada, o aumento das concentrações de fosforo e nitrogênio pode estar associado as práticas agrícolas, irrigação, uso intensivo de fertilizantes, revolvimento do solo, erosão do solo, e a drenagem. Promovem o crescimento excessivo de algas em consequência do processo de eutrofização, e expõe ainda 
a problemas com a redução do oxigênio dissolvido e aumento da taxa de decomposição da matéria orgânica (Schindler et al., 2012).

Ao discorrer sobre fundamentos da qualidade e tratamento da água Libânio (2010) reportou que o elemento fósforo, por ser menos abundante que o nitrogênio, se constitui, na maioria das vezes, como o fator limitante ao desenvolvimento de algas e plantas no meio aquático.

O oxigênio dissolvido (OD) apresentou valor médio de $4,8 \mathrm{mg} \mathrm{L}^{-1}$ um pouco inferior ao valor determinado na Resolução CONAMA 357/2005 ( $\geq 5 \mathrm{mg} \mathrm{L}^{-1}$ ), para águas doces Classe II. Os níveis de OD atenderiam as classes III e IV, $\geq 4$ $\mathrm{mg} \mathrm{L} \mathrm{L}^{-1} \mathrm{e} \geq 2 \mathrm{mg} \mathrm{L}^{-1}$, respectivamente (Brasil, 2005).

Resultados de oxigênio dissolvido dentro dos padrões da Resolução CONAMA 357/2005 (Brasil, 2005) foram obtidos por Sales et al. (2020) ao analisarem a qualidade da água da Bacia Escola Jacaré-Curituba no Estado de Sergipe, Sassoma et al. (2015) ao analisarem a qualidade da água do Rio Catumbela na Angola, por Valle Júnior et al. (2013) Rio Uberaba - MG, e por Vasconcelos et al. (2009) do Rio Acaraú - CE.

Nas águas naturais o oxigênio molecular dissolvido, $\mathrm{O}_{2}$, é o agente oxidante mais importante. Os peixes necessitam de no mínimo $5 \mathrm{mg} \mathrm{L}^{-1}$ de oxigênio dissolvido (OD) para se manterem vivos. A concentração de oxigênio pode variar com a temperatura, a solubilidade dos gases aumenta quando a temperatura diminui, logo águas de rios ou lago aquecidas artificialmente podem experimentar a poluição térmica por conter menos oxigênio que águas frias. Águas pouco profundas são continuamente reabastecidas de oxigênio através do fluxo de dos cursos d'água (Baird, 2002).

Já a DBO a qual é estabelecido valores $\leq 5 \mathrm{mg} \mathrm{L}^{-1} \mathrm{O}_{2}$, apresentou valor médio de $3,4 \mathrm{mg} \mathrm{L}^{-1} \mathrm{O}_{2}$, o que classificaria o ambiente como Classe I e II pela Resolução CONAMA 357/2005, já que os padrões são $\leq 3 \mathrm{mg} \mathrm{L}^{-1} \mathrm{e} \leq 5 \mathrm{mg} \mathrm{L}^{-1}$, respectivamente (Brasil, 2005).

A DBO apresentou valor máximo de 12,6 $\mathrm{mg} \mathrm{L}^{-1}$. Este é o parâmetro mais usual para medição da poluição orgânica, o oxigênio é consumido nas reações de oxidação (Braile \& Cavalcanti, 1993), isto explica a correlação negativa entre DBO e $\mathrm{OD}$, quanto maior a demanda por oxigênio, menor a disposição deste no meio.

A concentração média e o valor máximo de cloretos, 69 e 159,7 $\mathrm{mg} \mathrm{L}^{-1}$, respectivamente, estiveram abaixo do padrão estabelecido pela Resolução CONAMA 357/2005, que para todas as classes de água doce deve ser $\leq 250 \mathrm{mg} \mathrm{L}^{-1}$ (Brasil, 2005).

Segundo Tucci (2004) os cloretos ocorrem em todas as águas naturais, podendo ser o resultado de depósitos minerais, de contato com a água do mar, mas também da poluição por esgotos e resultante do retorno de águas utilizadas em irrigação. Apesar de não representar um prejuízo à saúde, em quantidades razoáveis, pode transmitir um sabor salgado a água.

Os teores médios de sólidos totais estiveram abaixo do valor máximo permitido na Resolução CONAMA 357/2005, $\leq$ $500 \mathrm{mg} \mathrm{L}^{-1}$, para todas as classes de água doce, já o valor máximo, $706 \mathrm{mg} \mathrm{L}^{-1}$ não atenderia aos padrões, situação similar foi observada na variável turbidez, onde o a média, $90,9 \mathrm{mg} \mathrm{L}^{-1}$, atenderia os padrões para as Classes 2 e 3 mas o valor máximo, $710 \mathrm{mg} \mathrm{L}^{-1}$ extrapolaria aos limites para todas as classes que é $\leq 100 \mathrm{mg} \mathrm{L}^{-1}$ (Brasil, 2005).

Avnimelech (1999) ao avaliar a relação carbono/nitrogênio como elemento de sistemas de aquiculturam citam que águas drenadas de lotes piscícolas podem apresentar características semelhantes a efluentes domésticos, com elevada carga orgânica, grande concentração de sólidos, podendo provocar inúmeras alterações nos corpos hídricos.

A passagem da água por áreas agrícolas irrigadas resulta em problemas de qualidade, devido ao manejo inadequado do solo e da água (Monteiro et al., 2019; Silva et al., 2019).

$\mathrm{O}$ pH variando de 6,0 a 8,5 é intervalo usual de água de irrigação (Almeida, 2010) e o adequado à manutenção da vida aquática (Libânio, 2010). Na área em estudo o pH variou de 5,6 a 8,5, tendo como valor médio 7,2, esta média atende ao intervalo de 6 a 9, estabelecido na Resolução CONAMA 357/2005, para todas as classes de água doce (Brasil, 2005). Já o valor mínimo, 5,6, não atende aos padrões legais, tampouco, os padrões de agricultura. 
Para Vasconcelos et al. (2009) do ponto de vista químico, a importância da água na natureza, reflete-se no comportamento do hidrogênio e da hidroxila, que são responsáveis pelo equilíbrio químico entre estes e a molécula de $\mathrm{H}_{2} \mathrm{O}$.

O valor máximo de nitrato foi de 0,6, atendendo ao padrão legal da Resolução CONAMA 357/2005 que estabelece $\leq$ $10 \mathrm{mg} \mathrm{L}^{-1}$ (Brasil, 20005). Resende (2002) ao detalhar a contaminação da água por atividades agropecuárias, descreve o nitrato $\left(\mathrm{NO}^{3}\right.$-) como a principal forma de nitrogênio associada, porque o ânion nitrato, tende a permanecer mais em solução, principalmente nas camadas superficiais do solo. Além disso o excesso de $\mathrm{N}$ e $\mathrm{P}$ pode causar eutrofização.

Marmontel \& Rodrigues (2015), ao avaliarem e compararem a qualidade da água de quatro nascentes em diferentes coberturas de terra e conservação da vegetação no Córrego Pimenta afluente do Rio Paraíso, na Fazenda Experimental São Manuel, pertencente à UNESP, reportaram que concentrações de nitrato podem estar disponíveis no meio devido ao uso de fertilizantes e excrementos de animais que são carreados pelo escoamento superficial para os cursos d'água.

Considerando o valor máximo de 870 UFC para coliformes termotolerantes, percebeu-se que as concentrações se

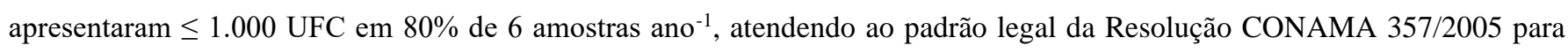
Classe II (Brasil, 2005). Deutsch et al. (2016), ao monitorarem a qualidade da água numa comunidade rural das Filipinas, com mais de 50\% do uso e ocupação do solo de terras agrícolas, detectaram teores de coliformes termotolerantes, especificamente a bactéria E.coli, na ordem de 100 a 200 UFC.

A cor aparente oscilou entre 11 e $2.408 \mathrm{UC}$, seu valor médio foi de $173,3 \mathrm{mg} \mathrm{L}^{-1}$, não atendendo ao limite legal da Resolução CONAMA 357/2005 para todas as classes de água doce que é < $75 \mathrm{mg} \mathrm{L}^{-1}$ (Brasil, 2005). Para efeito comparativo, considerando o padrão de potabilidade, a água deve apresentar intensidade de cor aparente inferior a cinco unidades, já em águas naturais varia de 0 a 200 UC (Brasil, 2014). A cor aparente pode sofrer interferência da turbidez, ambas variáveis influenciadas pela sazonalidade, fato que pode ser explicado pelo aumento do carreamento de sedimentos em período chuvoso.

Dentre as causas da cor nos mananciais, ocorrem as causas naturais, proveniente da matéria orgânica natural (decomposição vegetal, algas, tanino, lignina e os minerais dissolvidos “complexo de ferro e manganês") e antrópicas (lançamento de efluentes) (Von Sperling, 2007; Skoronski et al., 2014).

\section{Conclusão}

A avaliação quanto ao atendimento dos padrões legais estabelecidos na Resolução CONAMA 357/2005 permitiu identificar que alguns parâmetros não atenderam aos limites preconizados na legislação para nenhuma das classes de água doce, em especial os parâmetros de fósforo total e cor que ficaram muito acima dos limites estabelecidos.

O valor máximo de condutividade elétrica encontrado neste estudo indica uso restrito ligeiro a moderado para fins de irrigação.

A análise da qualidade da água permitiu evidenciar que o aporte de águas drenadas do Perímetro de Irrigação Cotinguiba/Pindoba contribuiu com o aumento da concentração de algumas variáveis, por isso, a importância de manter um plano de gestão ambiental para mitigar os impactos, das atividades de agricultura e piscicultura, na qualidade das águas.

\section{Referências}

Avnimelech, Y. (1999). Carbon/nitrogen ratio as a control element in aquaculture systems. Aquaculture, 176(3-4), 227-235. https://doi.org/10.1016/S00448486(99)00085-X

Ayers, R. S. \& Westcot, D. W. (1994). Water quality for agriculture. (3a ed.), Rome: FAO, 1994. 174p.

Baird, C. (2002). Química Ambiental. (2a ed.), Bookman, 622p.

Braile, P. M. \& Cavalcanti, J. E. W. A. (1993). Manual de Tratamento de Águas Residuárias Industriais. CETESB. 764p.

Brasil (2005). Ministério do Meio Ambiente: Resolução CONAMA No 357 de 17 de março de 2005. Brasília: Ministério do Meio Ambiente. 23p. 
Brasil. (2014). Ministério da Saúde: Manual de controle da qualidade da água para técnicos que trabalham em ETAS. Brasília: Ministério da Saúde/Funasa. $116 \mathrm{p}$.

Brito, F. B.; Silva, T. M. M.; Vasco, A. N.; Aguiar Netto, A. O. \& Carvalho, C. M. (2016). Impactos da produção do arroz inundado na qualidade da água do Rio Betume, Sergipe. Revista Agropecuária Técnica, 37(1), 44-54. https://doi.org/10.25066/agrotec.v37i1.25254

Brito, L. T. L.; Srinivasan, V. S.; Silva, A. S.; Galvão, C.O. \& Ribeiro, P. H. B. (2003). Variabilidade da qualidade da água do rio Salitre. Anais... Simpósio brasileiro de capacitação e maneijo da água de chuva, 4. Juazeiro: ABCMAC.

Buzelli, G. M.; Cunha-Santino, M. B. (2013). Análise e diagnóstico da qualidade da água e estado trófico do reservatório de Barra Bonita (SP). Revista Ambiente \& Água, 8(1), 186-205. https://doi.org/10.4136/ambi-agua.930

Carvalho, L. L. S., Lacerda, C. F., Carvalho, C. M., Lopes, F. B., Andrade, E. M. \& Gomes Filho, R. R. (2020). Variabilidade espaço-temporal da qualidade das águas subterrâneas em área irrigada no semiárido brasileiro. Research, Society and Development, 9(8). https://doi.org/10.33448/rsd-v9i8.5786

Carvalho, L. L. S.; Lacerda, C. F.; Lopes, F. B.; Carvalho, C. M.; Gomes Filho, R. R. \& Araújo Filho, R. N. (2017). Influence of Prolonged Drought on Groundwater Quality: Irrigated Perimeter of Lower Acaraú - State of Ceará- Northeast of Brazil. Journal of Experimental Agriculture International, 18(3), 114. https://doi.org/10.9734/JEAI/2017/36480

CODEVASF. (2005). Companhia de Desenvolvimento dos Vales do São Francisco e do Parnaíba: Diagnostico Ambiental dos Perímetros Irrigados da CODEVASF. Aracajú: $4^{\mathrm{a}}$ Superintendência Regional, $134 \mathrm{p}$.

CODEVASF. (2006). Companhia de Desenvolvimento dos Vales do São Francisco e do Parnaíba: Avaliação da Qualidade das Águas do Perímetros Irrigado de Cotinguiba/Pindoba - CODEVASF. Relatório Final. Aracajú: $4^{\mathrm{a}}$ Superintendência Regional, $70 \mathrm{p}$.

CODEVASF. (2014). Companhia de Desenvolvimento dos Vales do São Francisco e do Parnaíba: Programa de Avaliação das Águas e Sedimentos dos Perímetros Irrigados Cotinguiba/Pindoba-CODEVASF. Relatório Final. Aracajú: $4^{\text {a }}$ Superintendência Regional, $44 \mathrm{p}$.

Cunha, D. G. F., Calijuri, M. C.; Lamparelli, M. C., Menegon Jr., N, \& Povinelli, J. (2013). Resolução CONAMA 357/2005: análise espacial e temporal de não conformidades em rios e reservatórios do estado de São Paulo de acordo com seus enquadramentos (2005-2009). Revista de Engenharia Sanitária e Ambiental, 18(2), 159-168. https://doi.org/10.1590/S1413-41522013000200008

Deutsch, W., Busby, A. L., Orprecio, J., Labis, J. P. \& Cequiña, E. Y. (2016). Community-based water quality monitoring: From data collection to sustainable management of water resources. Seeking Sustainability, cap.07, 138-160.

Hu, Q.; Yang, Y.; Han, S. \& Wang, J. (2019). Degradation of agricultural drainage water quantity and quality due to farmland expansion and water-saving operations in arid basins. Agricultural Water Management. 213, 185-192. https://doi.org/10.1016/j.agwat.2018.10.019

IBGE. (2011). Instituto Brasileiro de Geografia e Estatística: Projeto de Levantamento e Classificação do Uso da Terra no Estado de Sergipe. Relatório Técnico. Rio de Janeiro: IBGE, 195p.

Libânio, M. (2010). Fundamentos de Qualidade e Tratamento de Água. 1, (3a ed.), Editora Átomo, 444 p.

Lisboa, E. G.; Carvalho, J. M. C. M. \& Mendes, R. L. R. (2016). O Uso da Geoestatística na Avaliação dos Parâmetros Hidrogeológicos para Compor o Mapa de Vulnerabilidade Intrínseca de Aquíferos. RBRH [online], 21(1), 188-199. https://doi.org/10.21168/rbrh.v21n1.p188-199

Lomba, A.; Strohbach, M.; Jerrentrup, J. S.; Daurber, J.; Klimek, S. \& McCracken, D. I. (2017). Making the best of both worlds: Can high-resolution agricultural administrative data support the assessment of High Nature Value farmlands across Europe? Ecological Indicators, 72, 118-130. https://doi.org/10.1016/j.ecolind.2016.08.008

Maia, K. P. (2014). Otimização do índice de qualidade da água por meio de análise estatística multivariada. Dissertação de Mestrado em Engenharia Ambiental. Ouro Preto: UFOP, 109p.

Marmontel, C. V. F. \& Rodrigues, V. A. (2015). Parâmetros Indicativos para Qualidade da Água em Nascentes com Diferentes Coberturas de Terra e Conservação da Vegetação Ciliar. Revista Floresta e Ambiente, 22(2), 171-181. https://doi.org/10.1590/2179-8087.082014

Medeiros, R. B.; Pinto, A. L. \& Miguel, A. E. S. (2013). Implicações da vulnerabilidade ambiental na qualidade das águas superficiais da Bacia do Córrego das Antas, Tupi Paulista/SP. Fórum Ambiental da Alta Paulista, 9(2), 34-50. http://dx.doi.org/10.17271/19800827922013538

Menezes, J. P. C.; Bittencourt, R. P.; Farias, M. S.; Bello, I. P.; Fia, R. \& Oliveira, L. F. C. (2016). Relação entre padrões de uso e ocupação do solo e qualidade da água em uma bacia hidrográfica urbana. Engenharia Sanitária e Ambiental, 21(3), 519-534. https://doi.org/10.1590/S1413-41522016145405

Monteiro, A. S. C; Nascimento R. S.; Sales, J. M. J.; Silva, I. S. \& Aguiar Netto, A. O. (2019). Qualidade da água dos rios São Francisco e Jacaré por meio de análise multivariada. Anais... In: Simpósio Brasileiro De Recursos Hídricos, 23, Foz do Iguaçu: ABRH 2019.

Naghettini, M. \& Pinto, E. J. A. (2007). Hidrologia Estatística. CPRM, 552p.

Oliveira, M. D. (2002). Impacto do sedimento sobre o desenvolvimento do perifíton no Rio Taquari, Pantanal, MS. Boletim de pesquisa 37. Corumbá: Embrapa Pantanal. 20p.

Queiroz, M. M. F.; Iost, C. Gomes, D. S. \& Vila Boas, M. A. (2010). Influência do uso do solo na qualidade da água de uma microbacia hidrográfica rural. Revista Verde, 5(4), 200-210.

Resende, A. V. (2002). Agricultura e qualidade da água: contaminação da água por nitrato. Documentos 57. Planaltina: Embrapa Cerrados. 29p. 
Sabino, C. V. S.; Lage, L. V. \& Almeida, K. C. B. (2014). Uso de métodos estatísticos robustos na análise ambiental. Revista de Engenharia Sanitária e Ambiental, 19(Edição Especial), 87-94. https://doi.org/10.1590/S1413-41522014019010000588

Sales, J. M. J.; Aguiar Netto, A. O.; Monteiro, A. S. C. \& Carvalho, C. M. (2020). Variabilidade espaço-temporal da qualidade da água em área de agricultura irrigada. Revista Brasileira de Agricultura Irrigada, 14(3), 4071-4085. https://doi.org/10.7127/rbai.v14n101167

Sassoma, I. T. L.; Sousa, I. F.; Aguiar Netto, A. O. \& Carvalho, C. M. (2015). Avaliação temporal e espacial de caracteristicas físico-químicas em águas superficiais do Rio Catumbela, Angola. Revista Brasileira de Agricultura Irrigada, 9(3), 113-126. https://doi.org/10.7127/rbai.v9n300295

Schindler, D. W.; Hecky, R. E. \& McCullough, G. K. (2012). The rapid eutrophication of lake winnipeg: greening under global change. Journal of Great Lakes Research, 38(2), 6-13. https://doi.org/10.1016/j.jglr.2012.04.003

Silva, A. J.; Aguiar Netto, A. O.; Lucas, A. A. T.; Araújo, R. R. (2019). Recuperação de solo salino-sódico no semiárido brasileiro. In: Aguiar Netto, A. O.; Lima, A. K. V. O.; Santos, T. I. S. (Org.). Opará. 1ed. Aracaju: Criação Editora, 135-146.

Singh, A. Environmental problems of salinization and poor drainage in irrigated areas: management through the mathematical models. (2019). Journal of Cleaner Production, 206, 572-579. https://doi.org/10.1016/j.jclepro.2018.09.211

Skoronski, E.; Niero, B.; Fernandes, M.; Alves, M. V. \& Trevisan, V. (2014). Study of the application of tannin in the treatment of drinking water from the Tubarão River at Tubarão, SC. Ambiente \& Água, 9(4), 679-687. https://doi.org/10.4136/ambi-agua.1303

Trindade, A. L. C; Almeida, C. B. A.; Barbosa, P. E. \& Oliveira, S. M. A. C. (2017). Tendências temporais e espaciais da qualidade das águas superficiais da sub-bacia do Rio das Velhas, estado de Minas Gerais. Revista de Engenharia Sanitária e Ambiental, 22(1), 13-24. http://dx.doi.org/10.1590/s141341522016131457

Tucci, C. E. M. (2004). Hidrologia - ciência e aplicação. (3a ed.), Editora da Universidade. 943p.

Valle Júnior, R. F.; Abdala, V. L.; Guidolini, J. F.; Siqueira, H. E. \& Candido, H. G. (2013). Diagnostico temporal e espacial da qualidade das aguas superficiais do Rio Uberaba - MG. Caminhos de Geografia, 14(45), 01-11.

Van Vliet, M. T. H., Flörke, M. \& Wada, Y. (2017). Quality matters for water scarcity. Nature Geoscience, 10(11), 800-802. http://dx.doi.org/10.1038/ngeo3047

Vasconcelos, R. S.; Leite, K. N.; Carvalho, C. M.; Eloi, W. M.; Silva, L. M. F. \& Feitosa, H. O. (2009). Qualidade da água utilizada para irrigação na extensão da microbacia do baixo Acaraú. Revista Brasileira de Agricultura Irrigada, 3(1), 30-38. https://doi.org/10.7127/rbai.v3n100014

Villanueva, T. C. B.; Leal, L. R. B.; Zucchi, M. R.; Azevedo, E. G. \& Villanueva, P. R. (2015). Diagnóstico da qualidade das águas subterrâneas e elaboração do mapa de uso e ocupação dos solos na região de Irecê - BA. Águas Subterrâneas, 29 (1), 30-41. https://doi.org/10.14295/ras.v29i1.27932

Von Sperling, M. (2007). Estudos de modelagem da qualidade da água de rios. 7. UFMG, 452p.

Xie, Y. L.; Xia, D. X.; Ji, L.\& Huang, G. H. (2018). An inexact stochastic-fuzzy optimization model for agricultural water allocation and land resources utilization management under considering effective rainfall. Ecological Indications, 92, 301-311. http://dx.doi.org/10.1016/j.ecolind.2017.09.026

Zucco, E.; Pinheiro, A.; Soares, P. A. \& Deschamps, F. C. (2012). Qualidade das águas em uma bacia agrícola: subsídios ao programa de monitoramento. Revista de Estudos Ambientais, 14(3), 88-97. http://dx.doi.org/10.7867/1983-1501.2012v14n3p88-97 